\title{
Time to Radicle Protrusion Does Not Correlate with Early Seedling Growth in Individual Seeds of Impatiens and Petunia
}

\author{
Manjul Dutt and Robert Geneve ${ }^{1}$ \\ Department of Horticulture, University of Kentucky, Lexington, KY 40546
}

\begin{abstract}
AdDitional INDEX words. digital images, seed vigor, sequential imaging, flat-bed scanner, Impatiens wallerana, Petunia $\times$ hybrida

ABstract. Impatiens (Impatiens wallerana Hooker F.) and petunia (Petunia $\times$ hybrida Hort. Vilm.) seeds were imaged using a flat-bed scanner interfaced with a personal computer programmed to capture images every hour. Images were used to measure time to radicle protrusion and seedling growth. Time to radicle protrusion was calculated as time to $\mathbf{5 0 \%}$ germination or as actual germination for each seed. Seedling growth after germination was calculated from linear regression of growth over time. Radicle protrusion and seedling growth were evaluated as indicators of seed vigor. Both were good indicators of seed vigor in impatiens seed lots. These measurements of vigor were highly correlated for each impatiens seed lot and for pooled seed lots. However, there was little or no correlation between time to radicle protrusion and seedling growth on an individual seed basis. The relationship between germination speed and seedling growth rate observed in impatiens was confirmed in two petunia seed lots. This study supports the use of time to radicle emergence and seedling growth as good indicators of seed vigor. However, it appears that different aspects of seed vigor may be measured by these indicators because there was no relationship between time to radicle protrusion and seedling growth rate on an individual seed basis.
\end{abstract}

In seed lots with high viability, the ability to produce usable seedlings under less than optimal germination conditions is related to seed vigor. Thus, seed vigor testing is an essential tool used to evaluate commercial seed lots. The most common vigor tests are based on germination behavior (Hampton and TeKrony, 1995). These include normal germination percentage after a stress imposition, germination speed (time to radicle protrusion), and early seedling growth following germination. Tests that measure germination speed or seedling growth appear to have the widest adaptability across the large number of commercially grown small-seeded flower species.

Germination speed has been used as an indicator of seed vigor, especially in seed priming experiments (Geneve, 2005), and it is an important measurement used to model seed germination (Bradford, 1990). However, the actual time of radicle protrusion can be difficult to determine accurately because time intervals between evaluations is limited by the technician's time and can be as long as $24 \mathrm{~h}$.

Seedling growth is measured as length, area, or dry weight at periodic times after imbibition. Vigor tests for seedling growth usually require growing seedlings on a slant-board to generate straight seedlings that are hand measured by an analyst (Smith et al., 1973). It has been used successfully to test vigor in a number of small-seeded vegetable crops (Finch-Savage, 1986; McCormac et al., 1990; Perry, 1981; Smith et al., 1973). These studies have established a strong correlation between radicle

Received for publication 22 Sept. 2006. Accepted for publication 28 Jan. 2007. Seeds for this study were generously supplied by Sakata Seeds, and Ball Seed, Inc. This work was partially funded through a grant from the Gloeckner Foundation. The cost of publishing this paper was defrayed in part by the payment of page charges. Under postal regulations, this paper therefore must be hereby marked advertisement solely to indicate this fact.

University of Kentucky Experiment Station publication \#05-11-086.

${ }^{1}$ Corresponding author. E-mail: rgeneve@uky.edu. growth and seed vigor (Bingham et al., 1994). Woodstock (1969) concluded that seedling growth rate is a sensitive measure of seed vigor but is difficult to incorporate in routine vigor testing because it is too labor intensive to evaluate seedling growth over time.

Germination speed and early seedling growth are key parameters for describing seed lot quality beyond standard germination. However, the fundamental relationship between those seeds that germinate rapidly and their subsequent early seedling growth has not been studied in detail due to the limitations of accurately and repeatedly evaluating these parameters. Use of computer-aided digital imaging of seed germination has overcome some of these limitations for evaluating seed germination (McDonald et al., 2001). A process for nondestructive, repeated measurements of individual seeds (seedlings) would enhance the ability to study these two measures of germination. Therefore, the objective of this research was to develop a sequential imaging system to evaluate seed germination and seedling growth on an individual seed basis. Sequential imaging was used to evaluate the relationship between germination speed and seedling growth rate on a population and an individual seed basis in seed lots of different vigor.

\section{Materials and Methods}

SEED SOURCE AND AGING. Untreated and primed impatiens (cv. Impact White) seeds from Sakata Seeds America (Morgan Hill, Calif.) and two high-germinating ( $>95 \%)$ numbered seed lot accessions of petunia from Ball Seed (East Chicago, Ill.) were placed in airtight plastic containers on receipt and stored at $4{ }^{\circ} \mathrm{C}$. Portions of the untreated and primed seed lots were aged for 3 or 6 months by placing them in closed containers at $25{ }^{\circ} \mathrm{C}$. 
Sequential Imaging. Nine impatiens seeds or 25 petunia seeds were sown into four replicate 6 -cm-diameter petri dishes containing one piece of sterile transparent cellulose acetate film wetted with $1 \mathrm{~mL}$ of sterile water (Oakley et al., 2004). Petri dishes were sealed with Parafilm and placed in a single germination chamber held at a constant $25{ }^{\circ} \mathrm{C}$ at 80 $\mu \mathrm{mol} \cdot \mathrm{s}^{-1} \cdot \mathrm{m}^{-2}$ from cool-white fluorescent lamps. After $48 \mathrm{~h}$ for impatiens or at initial imbibition for petunia, dishes were placed on a HP Scanjet 5370 C flat-bed scanner with transparency adapter (Hewlett Packard, Palo Alto, Calif.) inside the growth chamber. The flat-bed scanner was interfaced with a personal computer using Windows 98SE (Microsoft Corp., Redmond, Wash.) operating system. A Visual Basic macro in SigmaScan Pro (SPSS, Chicago) captured images (300 dpi, $118 \mathrm{dots} / \mathrm{cm}$, color TIFF file format) every hour for up to $5 \mathrm{~d}$.

Germination speed was determined by examining each sequential image in SigmaScan Pro for visible radicle (hypocotyl) protrusion. Germination speed was the actual time (within $30 \mathrm{~min}$ ) to radicle protrusion for individual seeds or calculated on a population basis as the number of hours to observed radicle protrusion for $50 \%$ of the germinating population $\left(T_{50}\right)$.

Seedling growth was determined by evaluating images using SigmaScan Pro's trace function. Using the mouse, a linear overlay was traced for the length of the emerging hypocotyl and radicle. Cumulative length in pixels was converted to mm using a standard calibration image. Growth rate was calculated as the slope of the linear regression of seedling length measured after initiation of radicle protrusion for germinated seedlings every $4 \mathrm{~h}$ for $24 \mathrm{~h}$ for impatiens and every $2 \mathrm{~h}$ for $36 \mathrm{~h}$ for petunia. Similarly, a single length measurement was taken 6 or $3 \mathrm{~d}$ after the start of imbibition for impatiens and petunia, respectively.

\section{Results}

Before storage there were significant differences between untreated and primed impatiens seeds for time to radicle emergence, seedling growth rate, and seedling length after $6 \mathrm{~d}$ but no difference in germination percentage (Table 1). Aging had a major effect on all measures of seed lot quality and both untreated and primed seeds behaved in a similar pattern during storage (Table 1). After 6 months in storage, germination percentage was reduced to a greater degree in primed compared with untreated seeds, while germination speed, growth rate, and length after $6 \mathrm{~d}$ were not different.

There was a significant linear relationship between germination speed and seedling length and growth rate when all data from untreated, primed and aged seed lots were compared (Figs. 1 and 2). There was a significant but low correlation between germination speed calculated for individual seeds and growth rates for aged seeds (Table 1, Fig. 3). For non-aged seeds, there was no relationship between germination speed and subsequent seedling growth rate or seedling size after $6 \mathrm{~d}$ (Figs. 3 and 4).

The two petunia seed lots had similar germination and seedling growth rates (Table 2). Similarly to impatiens, neither seed lot showed a significant correlation between germination speed and growth rate on an individual seed basis, but there was a significant relationship between germination speed and growth after $3 \mathrm{~d}$.

\section{Discussion}

The quality of a seed lot can be described by its standard germination as well as its seed vigor [Association of Official Seed Analysts (AOSA), 1983]. Standard germination is measured as the percentage of seeds that germinate under nearoptimal conditions, while seed vigor has been described as those seed properties that determine the potential for rapid, uniform emergence and development of normal seedlings under a wide range of germination conditions (AOSA, 1993). Two aspects of rapid and uniform emergence are time to radicle protrusion and subsequent seedling growth. Therefore, it is understandable that both of these properties of seeds have been used to measure seed vigor (Geneve, 2005).

Table 1. Germination percentage, germination speed, seedling growth rate and length for primed or nonprimed impatiens 'Impact White' seeds aged for 0,3 , or 6 mo. at $25^{\circ} \mathrm{C}$.

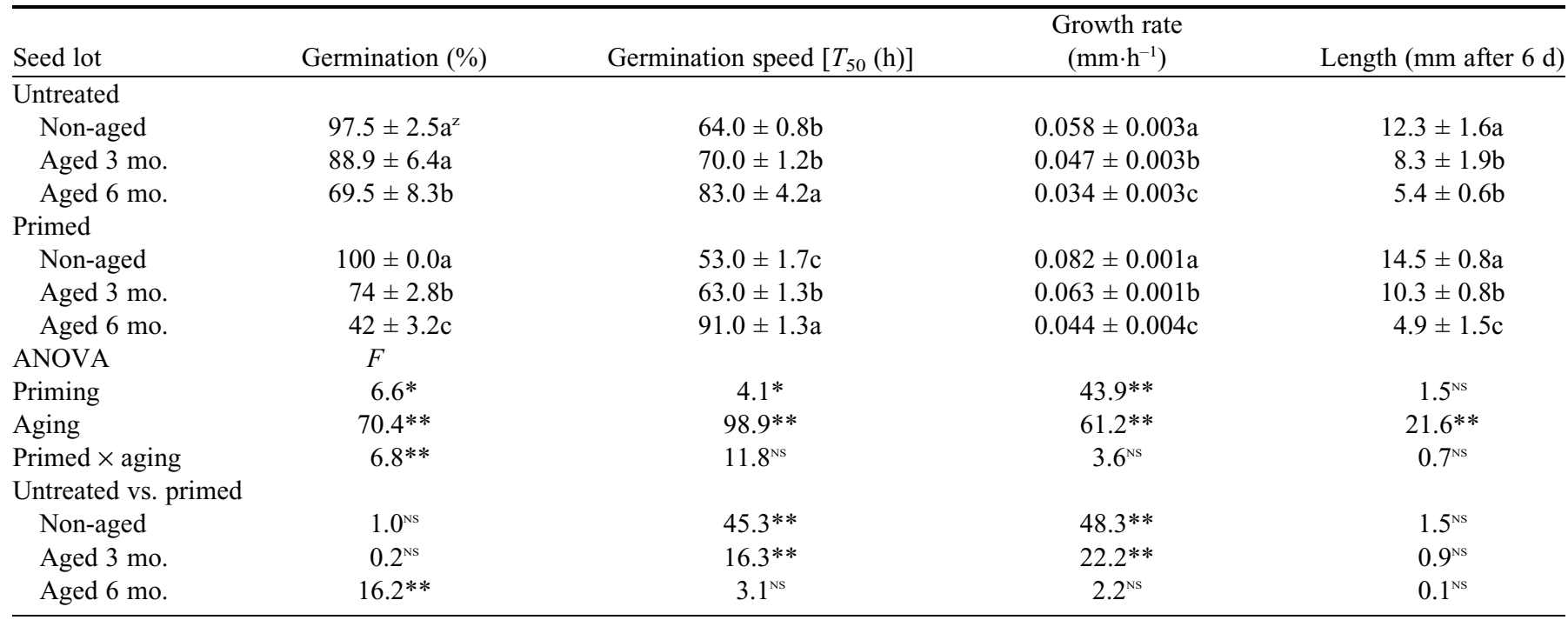

${ }^{\mathrm{z}}$ Mean \pm SE within untreated or primed seeds followed by the same letter were not different at $\alpha=0.05$ using Tukey's test.

${ }_{\text {Ns, }, * * *}$ Nonsignificant or significant at $P \leq 0.05$ or 0.01 , respectively. 


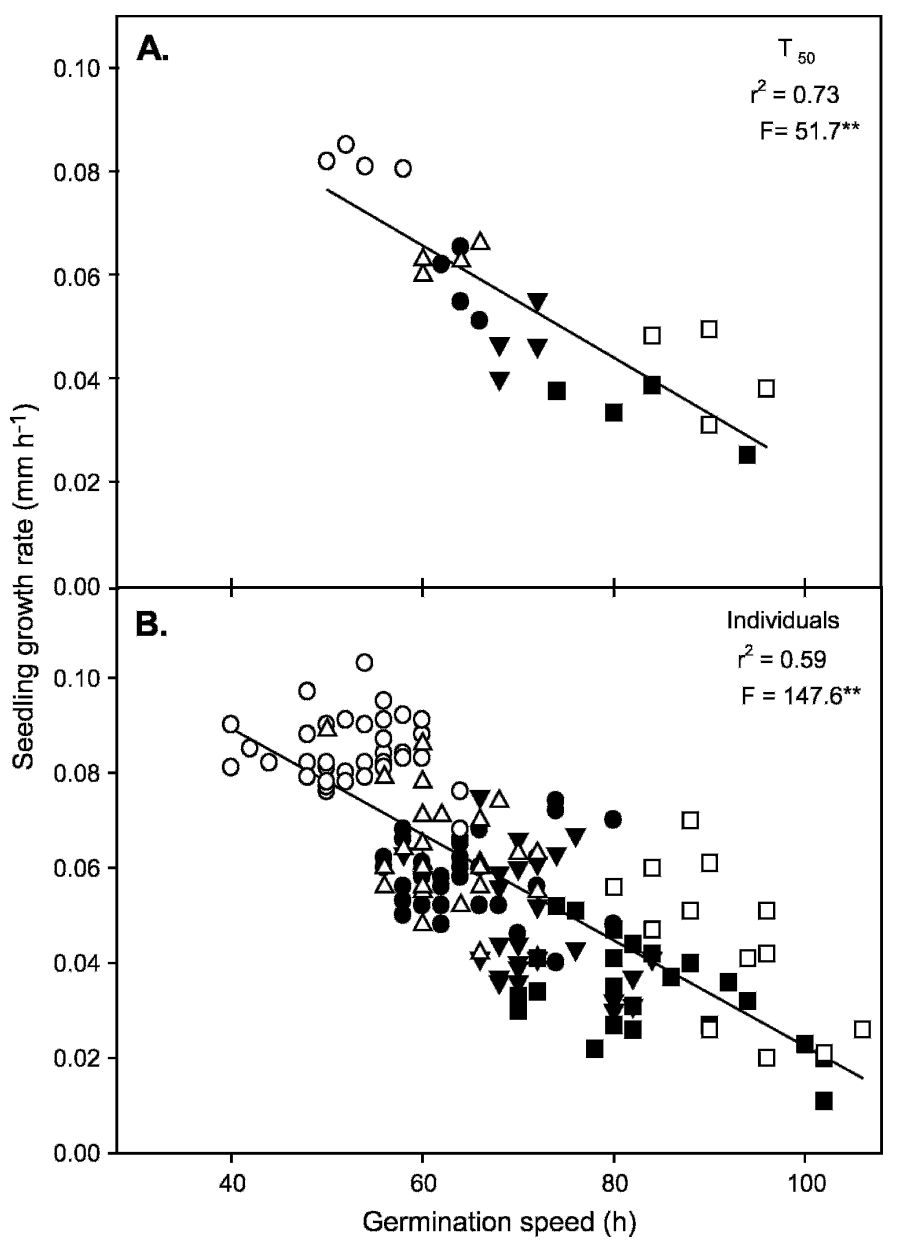

Fig. 1. Seedling growth rate in impatiens seed lots calculated over the first $24 \mathrm{~h}$ following radicle protrusion regressed against the time from imbibition to radicle protrusion for (A) time to $50 \%$ germination $\left(T_{50}\right)$ or $(\mathbf{B})$ each individual seed for untreated (open symbols) or primed (closed symbols)

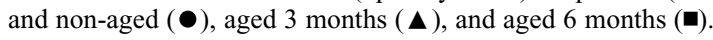

Germination speed has been used to evaluate germination enhancement in primed seeds and as an indicator of seed vigor (Dell'Aquila, 1987; Hacisalihoglu et al., 1999). Similarly, seedling growth rate has been used as a measure of seed vigor (Finch-Savage, 1986; Woodstock, 1969). Both were equally effective as indicators of seed vigor for seed lots of impatiens (Table 1; Oakley et al., 2004). Because germination speed and seedling length were effective in describing seed vigor, it was expected that they would be correlated measurements. There was a significant trend between these measures across all seed lots calculated on population and individual seed bases (Figs. 1 and 2). This relationship has also been observed in primed and aged wheat (Triticum durum Desf.) seeds, for which mean germination time and seedling length after $4 \mathrm{~d}$ were negatively correlated (Dell'Aquila, 1987). In contrast, seedling length $48 \mathrm{~h}$ after radicle protrusion was essentially unchanged in aged seed lots of lettuce (Lactuca sativa L.) that also showed reduced germination speed (Tarquis and Bradford, 1992).

On the basis of overall trends (see Figs. 1 and 2), it was expected that individual impatiens seeds that were fastest to germinate would also display fast seedling growth. However, there was a weak relationship between germination speed and seedling length for aged seeds and there was no such

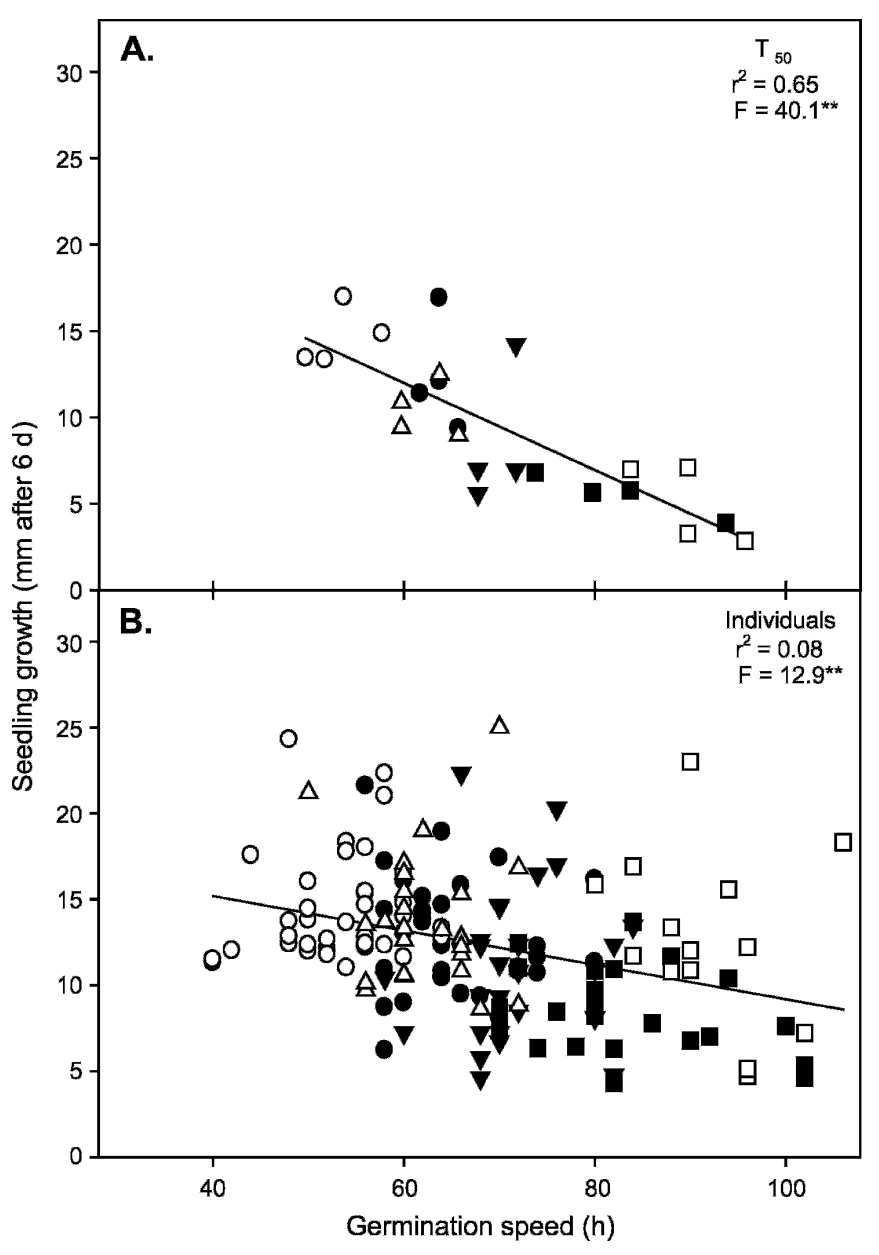

Fig. 2. Seedling length after $6 \mathrm{~d}$ following imbibition in impatiens seed lots regressed against the time from imbibition to radicle protrusion for (A) time to $50 \%$ germination $\left(T_{50}\right)$ or $(\mathbf{B})$ each individual seed for untreated (open symbols) or primed (closed symbols) and non-aged $(\bullet)$, aged 3 months $(\boldsymbol{\Delta})$, and aged 6 months (ש).

relationship for untreated and primed seeds before storage (Figs. 3 and 4). For example, in the untreated seed lot, seeds that germinated after $55 \mathrm{~h}$ had the same growth rate as seeds that germinated after $90 \mathrm{~h}$. Impatiens seeds are unusual in that they initiate germination by hypocotyl elongation, and the radicle does not protrude until the hypocotyl is several millimeters beyond the ruptured testa. Therefore, petunia seeds were evaluated to see if the observed poor relationship between germination speed and subsequent seedling growth rate was unique to impatiens. In the two seed lots of petunia that were evaluated, germination speed was not correlated with growth following germination (Table 2). This confirms the observation with impatiens (Fig. 3).

The early seedling growth rate from the time of radicle emergence was linear in impatiens (Oakley et al., 2004) and petunia (data not shown), which indicated that measuring seedling size after a predetermined time incorporates both aspects of germination speed and growth rate. Similar to growth rate after germination, seedling size after $6 \mathrm{~d}$ did not correlate with germination on an individual seed basis for impatiens (Fig. 4). However, there was a relationship between time to radicle protrusion and growth after $3 \mathrm{~d}$ in petunia. The difference may be due to the unique germination pattern in impatiens, where 


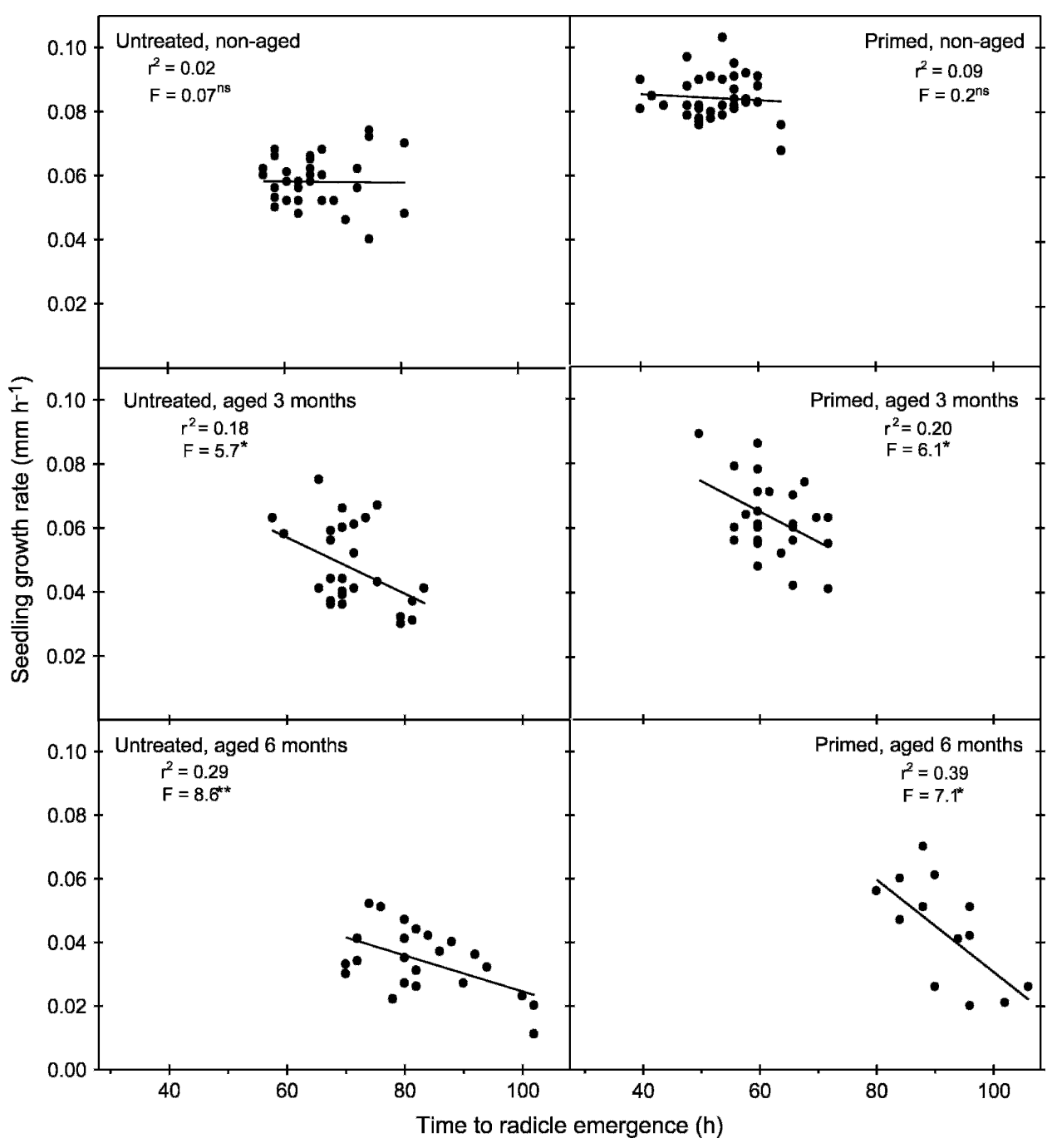

Fig. 3. Seedling growth rate calculated over the first $24 \mathrm{~h}$ following radicle protrusion regressed against the time from imbibition to radicle protrusion for each individual seeds in untreated, primed, and aged impatiens seed lots.

On an individual seed basis, germination speed and seedling growth rate may be measuring different aspects of vigor. Germination speed is a function of the ability of the radicle to penetrate its surrounding seed coverings. The time required to germinate is thought to be a function of the force generated by the embryo (termed the "growth potential") and a reduction in the physical strength of the surrounding seed coverings (Welbaum et al., 1998).

Seedling growth rate following radicle protrusion describes seed vigor because vigorous seeds are able to synthesize new materials and rapidly transfer these new products to the emerging embryonic axis, resulting in increased seedling dry weight accumulation (Copeland and McDonald, 2001).

The lack of correlation between germination speed and seedling length and growth rate on an individual basis (Figs. 3 and 4; Table 2) brings into question whether a technique that could separate early- and late- germinating seedlings would be useful for establishing faster growing seedlings. Finch-Savage (1986) followed seedling length on a slant board from seed populations germinating over a 6 -d period for several vegetable species. He did not see any significant differences in seedling length related to germination speed for the majority of the seeds within the seed lot that germinated in the first 3 or $4 \mathrm{~d}$.

seeds may have germinated by hypocotyl protrusion only and primary radicle elongation was delayed. This may have masked any relationship between germination speed of an individual seed and its growth after a set length of time.

The correlation between germination speed and seedling length in relation to seed vigor for seed populations observed here and in other studies (Dell'Aquila, 1987; Hill et al., 1989) appears to have masked the lack of correlation on an individual seed basis. Variation among seeds in a population reflects variation among seeds in the rate or extent of physiological or biochemical processes before radicle emergence. In a system that measured enzyme activity in individual tomato (Lycopersicon esculentum Mill.) seeds, Still and Bradford (1997) observed a large variation in enzyme activity between seeds that was not previously observed from pooled seed extracts. The biochemical differences among individual seeds before radicle protrusion indicated that results from bulk samples could be misleading if it is assumed that all seeds exhibit the average behavior. These studies point out that changes observed in seed populations may not reflect the range of changes occurring on a single seed basis.
However, in the small percentage of seeds that completed germination late, there was a reduction in seedling growth. His conclusion was that selecting early-germinating seeds would not dramatically alter subsequent seedling length or stand density because only a small percentage of seeds were in the late-germinating population that also showed slower seedling growth. Therefore, initial seed size, rather than time to radicle emergence, may be better correlated with seedling length, as suggested by density separation (Hill et al., 1989) and seed sizing studies (Smith et al., 1973).

The ability to see differences in individual seeds was possible because of the development of a sequential imaging system. Other systems have been developed to observe sequential images during germination, including time-sequence photography (Tomas et al., 1992) and machine vision using a charged coupled device (CCD) camera integrated with a personal computer (Dell'Aquila et al., 2000). Using sequential images to study imbibition in cabbage (Brassica oleracea L. var. capitata L.) seeds, the variation between individual seeds for rates of imbibition and time to complete germination was clearly observed (Dell'Aquila et al., 2000). The advantages 


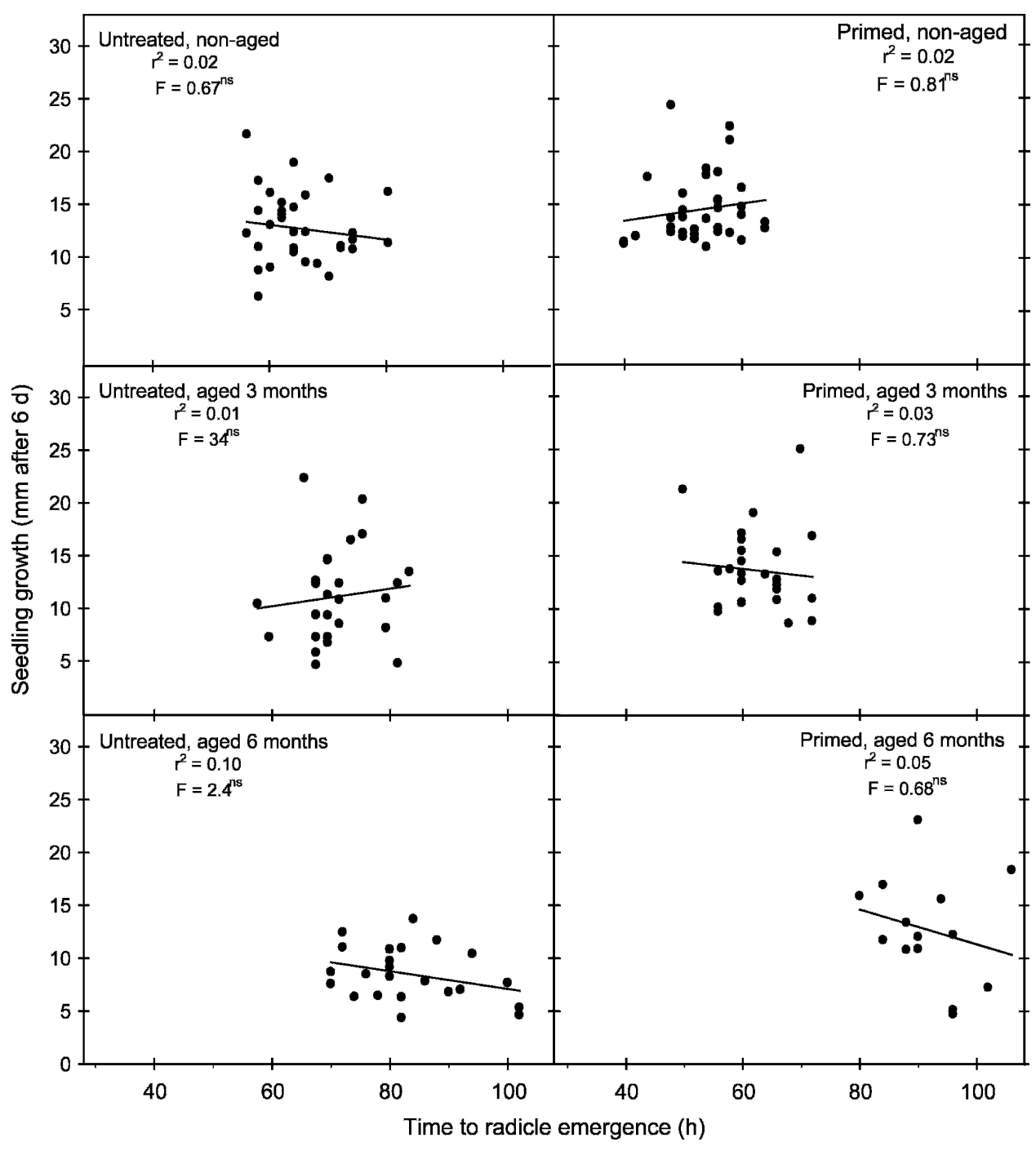

Fig. 4. Seedling length after $6 \mathrm{~d}$ following imbibition regressed against the time from imbibition to radicle protrusion for each individual seeds in untreated, primed, and aged impatiens seed lots.

Table 2. Germination speed, seedling growth rate, and length for two seed lots of petunia.

\begin{tabular}{|c|c|c|c|c|c|c|c|}
\hline \multirow[b]{2}{*}{ Seed lot } & \multirow{2}{*}{$\begin{array}{c}\text { Germination } \\
\text { speed }(d)\end{array}$} & \multirow{2}{*}{$\begin{array}{l}\text { Growth rate } \\
\left(\mathrm{mm} \cdot \mathrm{d}^{-1}\right)\end{array}$} & \multirow{2}{*}{$\begin{array}{l}\text { Length after } \\
3 \mathrm{~d}(\mathrm{~mm})\end{array}$} & \multicolumn{2}{|c|}{$\begin{array}{l}\text { Germination speed } \\
\text { vs. growth rate }\end{array}$} & \multicolumn{2}{|c|}{$\begin{array}{l}\text { Germination speed } \\
\text { vs. } 3 \text {-d length }\end{array}$} \\
\hline & & & & $r^{2}$ & $F$ & $r^{2}$ & $F$ \\
\hline 21 & $30.5 \pm 0.8^{z}$ & $1.9 \pm 0.07$ & $3.17 \pm 0.2$ & 0.01 & $0.5^{\mathrm{NS}}$ & 0.33 & $27.1 * *$ \\
\hline 15 & $32.9 \pm 0.8$ & $2.2 \pm 0.05$ & $3.11 \pm 0.1$ & 0.09 & $5.6^{\mathrm{NS}}$ & 0.52 & $64.9^{* *}$ \\
\hline
\end{tabular}

${ }^{\mathrm{z}}$ Mean $\pm \mathrm{SE}$

${ }^{* *}$ Significant linear trend at $P \leq 0.01$.

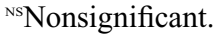

of using a flat-bed scanner over a CCD camera were pointed out previously (Geneve and Kester, 2001) and include lower cost, availability of commercial software, high resolution of small seeds, and no need to remove the lid on petri dishes to account for water condensation on the lid. The current study furthers the utility of this simple system by the development of a sequential imaging process that allows for samples to be collected hourly without technician input. This permits very accurate determinations of germination speed and seedling length on a single seed basis.

\section{Literature Cited}

Association of Official Seed Analysts (AOSA). 1983. Seed vigor testing handbook, Contribution No. 32. Association of Official Seed Analysts, Lincoln, NE. Association of Official Seed Analysts (AOSA). 1993. Rules for testing seeds. J. Seed Technol. 16:1-113.

Bingham, I.J., A. Harris, and L. MacDonald. 1994. A comparative study of radicle and coleoptile extension in maize seedlings from aged and unaged seeds. Seed Sci. Technol. 22:127-139.

Bradford, K.J. 1990. A water relations analysis of seed germination rates. Plant Physiol. 94:840-849.

Copeland, L.O. and M.B. McDonald. 2001. Principles of seed science and technology. 4th ed. Chapman \& Hall, New York.

Dell'Aquila, A. 1987. Mean germination time as a monitor of the seed ageing. Plant Physiol. Biochem. 25:761-768.

Dell'Aquila, A., J.W. Van Eck, and G.W.A.M. Van der Heijden. 2000. The application of image analysis in monitoring the imbibition process of white cabbage Brassica oleracea L. seeds. Seed Sci. Res. 10:163-169.

Finch-Savage, W.E. 1986. A study of the relationship between seedling characters and rate of germination within a seed lot. Ann. Appl. Biol. 108:441-444.

Geneve, R.L. 2005. Vigor testing in flower seeds, p. 311-332. In: M.B. McDonald and F. Kwong (eds.). Flower seeds, biology and technology. CAB International, London.

Geneve, R.L. and S.T. Kester. 2001. Evaluation of seedling size following germination using computer aided analysis of digital images from a flat bed scanner. HortScience 36:11171120.

Hacisalihoglu, G., A.G. Taylor, D.H. Paine, M.B. Hilderbrand, and A.A. Khan. 1999. Embryo elongation and germination rates as sensitive indicators of lettuce seed quality: priming and aging studies. HortScience 34:1240-1243.

Hampton, J.G. and D.M. TeKrony. 1995. Handbook of vigour test methods. 3rd ed. International Seed Testing Assn., Zurich, Switzerland. Hill, H.J., A.G. Taylor, and T.G. Min. 1989. Density separation of imbibed and primed vegetable seeds. J. Amer. Soc. Hort. Sci. 114:661-665.

McCormac, A.C., P.D. Keefe, and S.R. Draper. 1990. Automated vigour testing of field vegetables using image analysis. Seed Sci. Technol. 18:103-112.

McDonald, M.B., A.F. Evans, and M.A. Bennett. 2001. Using scanners to improve seed and seedling evaluations. Seed Sci. Technol. 29:683-689. 
Oakley, K., S.T. Kester, and R.L. Geneve. 2004. Computer-aided digital image analysis of seedling size and growth rate for assessing seed vigour in impatiens. Seed Sci. Technol. 32:907-915.

Perry, D.A. 1981. Handbook of vigour test methods. International Seed Testing Assn., Zurich, Switzerland.

Smith, O.E., N.C. Welch, and T.M. Little. 1973. Studies on lettuce seed quality: I. Effect of seed size and weight on vigor. J. Amer. Soc. Hort. Sci. 98:529-533.

Still, D.W. and K.J. Bradford. 1997. Endo- $\beta$-mannanase activity from individual tomato endosperm caps and radicle tips in relation to germination rates. Plant Physiol. 113:21-29.
Tarquis, A.M. and K.J. Bradford. 1992. Prehydration and priming treatments that advance germination rate also increase the rate of deterioration of lettuce seeds. J. Expt. Bot. 43:307-317.

Tomas, T.N., A.G. Taylor, and L.A. Ellerbrock. 1992. Timesequence photography to record germination events. HortScience 27:372.

Welbaum, G.E., K.J. Bradford, K.O. Yim, D.T. Booth, and M.O. Oluoch. 1998. Biophysical, physiological and biochemical processes regulating seed germination. Seed Sci. Res. 8:161-172.

Woodstock, L.W. 1969. Seedling growth as a measure of seed vigour. Proc. Intl. Seed Testing Assn. 34:273-280. 